International Journal of Current Advanced Research

ISSN: O: 2319-6475, ISSN: P: 2319 - 6505, Impact Factor: SJIF: 5.995

Available Online at www.journalijcar.org

Volume 6; Issue 4; April 2017; Page No. 3257-3259

DOI: http://dx.doi.org/10.24327/ijcar.2017.3259.0239

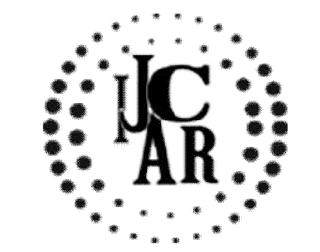

Review Article

\title{
CLINICAL APPLICATION OF CBCT IN ENDODONTICS-A REVIEW
}

\author{
Ashok Kumar and Pradeep S
}

Saveetha Dental College

\begin{tabular}{l}
\hline A R T I C L E I N F O \\
Article History: \\
Received $15^{\text {th }}$ January, 2017 \\
Received in revised form $19^{\text {th }}$ February, 2017 \\
Accepted $22^{\text {nd }}$ March, 2017 \\
Published online $28^{\text {th }}$ April, 2017
\end{tabular}

Key words:

CBCT, root canal, diagnostic tool, endodontics

\begin{abstract}
A B S T R A C T
This article aims to review about the clinical applications of CBCT. Diagnosis from CBCT influences clinical examination. $\mathrm{CBCT}$ is an emerging technology with the potential torevolutionize the diagnosis and management of endodontic problems. An increasing number of specific applications of CBCT in endodontics are being identified as use of this technology. CBCT is a relatively new method that produces three-dimensional information of the dental and surrounding structures. They have lesser radiation exposure than the traditional CT scans. CBCT is a advanced tool for diagnosing and managing endodontic problems, as well as for assessing root fractures, apical periodontitis, resorptions, perforations, root canal anatomy and the nature of the alveolar bone supporting the tooth.
\end{abstract}

Copyright $@ 2017$ Ashok Kumar and Pradeep S. This is an open access article distributed under the Creative Commons Attribution License, which permits unrestricted use, distribution, and reproduction in any medium, provided the original work is properly cited.

\section{INTRODUCTION}

Cone Beam Computed Tomography is a medical imaging technique consisting of X-ray computed tomography where the X-rays are divergent, forming a cone. ${ }^{(1)}$ CBCT was introduced first in the European market in $1996 .{ }^{(2)}$ Two dimensional imaging techniques have been used since 1896 . CBCT imaging is one of the recent techniques that is makes way to visualize the object in an equal planes three dimensionally. It is of low cost and of lower radiation exposure compared with conventional CT. CBCT helps in determining the root canal morphology by removal of the superimposed structures and showing normal anatomy and morphology of the root canal system without additional exposure with higher resolution. ${ }^{(3)}$

\section{Conventional Imaging Techniques and Its Limitations}

Radiography is essential for treatment of the pulp pathologies, bio-mechanical preparation of the root canal during RCT, obturation, and also in healing assessment. Imaging is needed in all stages of endodontic procedures. ${ }^{(4)}$ In Preoperative Assessment, the morphology of the tooth including location and number of canals, pulp chamber size and degree of calcification, root structure, direction and curvature, fractures, and the extent of dental caries can be observed only by imagining techniques, mostly radiographs. During therapy two radiographs may be performed. The first is for working length determination which is done by inserting files into the root canals to a length approximating till the apex. Second one is the 'master cone radiograph' which is done after biomechanical preparation to check the fit of the master cone. ${ }^{(5)}$

*Corresponding author: Ashok Kumar

Saveetha Dental College
A postoperative radiograph immediately after obturation is made to assess the material within the root canal. The prognosis of various abscesses can be assessed using radiographs. Here, the image produced is a two-dimensional (2D) representation of a three-dimensional (3D) object. Hence, geometric errors are very common.Healing of the periapical bone adjacent to obturated canals proves the success of the endodontic treatment. Even, studies showed that in the evaluation of bone healing in post endodontic treated cases have better evaluation through 3D techniques. ${ }^{(6)}$ Also, radiation exposure to the patient is high.

\section{CBCT in Endodontics}

CBCT beats the impediments of traditional radiography. This imaging framework in Endodontics has its own points of interest, consolidated with the lessened cost and size of CBCT when contrasted and ordinary CT. CBCT have seen an expanded take-up in this type of imaging in dental practices in late years. ${ }^{(1)}$ With CBCT turning into a perpetually available part of the endodontist's armamentarium, it is critical to know about the uses of this type of imaging strategy in overseeing endodontic problems. ${ }^{(7)} \mathrm{CBCT}$ is altogether more touchy than conventional radiography in the recognition of apical periodontitis in humans. ${ }^{(8)}$

At the point when utilized for preoperative appraisal, CBCT imaging gives exceedingly itemized data on the whole tooth structure, including the area and number of root canals, chamber size and level of calcification, heading and shape of root morphology, tooth and root cracks, and imperfections. Facilitate, it can give understanding into root resorption, the impacts of periradicular and periapical abscesses, and in addition the potential for inconveniences. 
$\mathrm{CBCT}$ is a precious endodontic device for use some time recently, before and after treatment. Once a treatment plan has been resolved, CBCT can be utilized to guarantee that metallic files set into the root canal are the proper size and shape. Taking after a treatment, $\mathrm{CBCT}$ can then give quick investigation, guaranteeing that the obturation material is sufficiently and fittingly arranged inside the root canal. It additionally offers a standard for knowing the healing, surgical and re-treatment options.

CBCT demonstrates exactness, which straightforwardly and emphatically impacts clinical choices, builds speed of treatment, and enhances efficiency and patient results. With CBCT innovation, the practice is engaged with prompt access to exact 3-D pictures of anatomical structures, basic to exact conclusions, more viable treatment planning, expanded case acknowledgment, and better follow up for the patient. ${ }^{(16-}$ 24)

\section{Advantages of Cbct}

Various researches carried out have increased the knowledge about CBCT has been proven. Recently CBCT are agreeable, time saving, as well as the reduced patient dose and high resolution images. Moreover, the most recent CBCT systems require a few seconds to take and reproduce the pictures. ${ }^{(9-11)}$ CBCT offers extensive ability to analyze a tooth resulting in very accurate assessment of all aspects of root and root canal morphology. ${ }^{(12)}$

\section{Limitations of CBCT in Endodontics}

A significant issue that can affect the image quality and diagnostic accuracy of CBCT images is the scatter and beam hardening artifacts caused by high density adjacent structures, such as enamel, and radiopaque materials such as metal posts, restorations and root filling materials. Additional artifacts that may obscure radiographic findings are patient movement during the scan and volume reconstruction. ${ }^{(13-15)}$

\section{CONCLUSION}

Thus, CBCT is a rising innovation with the possibility to upset the finding and administration of endodontic issues. An expanding number of particular utilizations of CBCT in endodontics are being distinguished as utilization of the innovation turns out to be more across the board. Besides, specialists of CBCT must be sufficiently prepared in CBCT radiology and additionally in the understanding of the pictures got, in light of the fact that the methodology is totally not the same as traditional radiography.

\section{References}

1. Scarfe WC, Farman AG, Sukovic P (February 2006). "Clinical applications of cone-beam computed tomography in dental practice". JCDA 72. PMID 16480609.

2. Hatcher DC (October 2010). "Operational principles for cone-beam computed tomography". JADA 141. PMID 20884933.

3. B.Vijayalakshmi.Root canal morphology of maxillary first and second premolar using cone beam computed tomography in south Indian population. IJPT| March2016 | Vol. 8 | Issue No.1 | 10387-10391.

4. Walton RE. Diagnostic imaging A. endodontic radiography. In: Ingle JI, Bakland LK, Baumgartner
JC, editors. Ingles' Endodontics. 6th edition. Hamilton, Canada: BC Decker; 2008. p. 554.

5. Rushton VE, Horner K, Worthington HV. Screening panoramic radiology of adults in general dental practice: radiological findings. BDJ, 2001; 190(9):495501.

6. Goldman M, Pearson AH, Darzenta N. Reliability of radiographic interpretations. Oral Surgery Oral Medicine and Oral Pathology. 1974; 38(2):287-293.

7. Conor DURACK, Shanon PATEL. Cone Beam Computed Tomography in Endodontics. Braz Dent $J$ (2012) 23(3): 179-191.

8. Yamamoto K, Ueno K, Seo K, Shinohara D. Development of dento-maxillofacial cone beam X-ray computed tomography system. Orthod Craniofac Res 2003;6: 160-162.

9. Calhoun PS, Kuszyk BS, David G. Heath DG, et al: Three-dimensional Volume Rendering of Spiral CT Data: Theory and Method. Radiographics. 1999; 19:745-764.

10. Scarfe WC, Farman AG: Voxel Vision using Maxillofacial CBCT: Clinical Applications of the Maximum Intensity Projection Retrieved August 2009.

11. Flygare L, Tsiklakis K, Whaites E, Horner K: Basic Principles for Use of Dental Cone Beam CT. Consensus Guidelines of the European Academy of Dental and Maxillofacial Radiology. January 2009.

12. Neeruj surathu, Sindhu Ramesh,. Root Canal Morphology of Maxillary First Molars Using Cone Beam Computed Tomography. IOSR. 2279-0861. 149- III (Sep. 2015)

13. Mora MA, Mol A, Tyndall DA, Rivera E. In vitro assessment of local tomography for the detection of longitudinal tooth fractures. Oral Surg Oral Med Oral Path Oral RadiolEndod 2007; 103:825-9.

14. Katsumata A, Hirukawa A, Noujeim M, Okumura S, Naitoh M, Fujishita M, Ariji E, Langlais RP. Image artifact in dental cone beam CT. Oral Surg Oral Med Oral RadiolEndod 2006; 101:652-7.

15. Barrett JF, Keat N. Artifacts in CT: recognition and avoidance. Radiographic 2004; 24: 1679-91.

16. Palomo J. M, Kan C H, Palomo LB, Hans MG: ThreeDimensional Cone Beam Computerized Tomography in Dentistry. Dentistry Today 2006; 25(11): 130-135.

17. FlygareL, Öhman A: Preoperative imaging procedures for lower wisdom teeth removal. Clin Oral Invest 2008; 12: 291-302.

18. Scarfe WC, Farman AG, Sukovic P: Clinical Applications of Cone-Beam Computed Tomography in Dental Practice. J Can Dent Assoc 2006; 72(1):75- 80.

19. Kau C. H, Richmond S, Palomo J. M, Hans M. G: Current Products and Practice. Three-dimensional cone beam computerized tomography in orthodontics. Journal of Orthodontics 2005; 32: 282-293.

20. Miracle AC, Mukherji SK: Conebeam CT of the Head and Neck, Part 2: Clinical Applications. Am J Neuroradiol 2009; 10.3174/ajnr.A1654

21. Kumar V, Ludlow JB, Mol A, Cevidanes L: Comparison of conventional and cone beam CT synthesized cephalograms. Dentomaxillofacial Radiology 2007; 36: 263-269. 
22. Baumgaertel S, Hans MG. Buccal cortical bone thickness for mini-implant placement $\mathrm{Am} J$ OrthodDentofacial Orthop 2009;136(2); 230-235

23. Harrell W.E: Three-dimensional diagnosis \& treatment planning: The use of 3D facial imaging and 3D cone beam CT in orthodontics and dentistry. Australasian Dental Practice. August 2007;102-113
24. Kim SH, Yoon HG, Choi YS, Hwang EH, Kook YA, Nelson G: Evaluation of interdental space of the maxillary posterior area for orthodontic mini- implants with cone-beam computed tomography. Am J OrthodDentofacialOrthoped 2009; 5: 635-641.

25. Gracco A, Lombardo L, Cozzani M, Siciliani G. Quantitative evaluation with CBCT of palatal bone thickness in growing patients. Prog Orthod 2006; 2:164-174.

\section{How to cite this article:}

Ashok Kumar and Pradeep S (2017) 'Clinical Application Of Cbct In Endodontics-A Review', International Journal of Current Advanced Research, 06(04), pp. 3257-3259.

DOI: http://dx.doi.org/10.24327/ijcar.2017.3259.0239 